OPEN ACCESS

Edited by:

Daniel Saban,

Duke University, United States

Reviewed by:

Jordi Ochando,

Icahn School of Medicine at

Mount Sinai, United States

Björn E. Clausen,

Johannes Gutenberg-Universität

Mainz, Germany

*Correspondence:

Kenji Kabashima

kaba@kuhp.kyoto-u.ac.jp

Specialty section:

This article was submitted to

Antigen Presenting Cell Biology,

a section of the journal

Frontiers in Immunology

Received: 06 April 2018

Accepted: 17 July 2018

Published: 30 July 2018

Citation:

Otsuka M, Egawa G and Kabashima K (2018) Uncovering the Mysteries of Langerhans Cells, Inflammatory Dendritic Epidermal

Cells, and Monocyte-Derived

Langerhans Cell-Like Cells in the Epidermis.

Front. Immunol. 9:1768 doi: 10.3389/fimmu.2018.01768

\section{Uncovering the Mysteries of Langerhans Cells, Inflammatory Dendritic Epidermal Cells, and Monocyte-Derived Langerhans Cell-Like Cells in the Epidermis}

\author{
Masayuki Otsuka', Gyohei Egawa ${ }^{1}$ and Kenji Kabashima ${ }^{1,2,3 *}$ \\ ${ }^{1}$ Department of Dermatology, Graduate School of Medicine, Kyoto, Japan, ${ }^{2}$ Singapore Immunology Network (SlgN), \\ Singapore, Singapore, ${ }^{3}$ Institute of Medical Biology (IMB), Agency for Science, Technology and Research (A*STAR), \\ Biopolis, Singapore, Singapore
}

The identity of Langerhans cells (LCS) has been called into question of late due to the increasing evidence that LCs originate from macrophage lineage instead of dendritic cell (DC) lineage as previously thought. For many years, LCs have been assumed to be DCs due to its migratory capabilities. However, recent studies have demonstrated that LCs are from macrophage lineage of the adult fetal liver (FL) progenitor. Bona fide LCs are now considered tissue-resident macrophages as they originate from the $\mathrm{FL}$ as shown by fate mapping models. In recent years, studies have shown that there are three types of antigen-presenting cells present in the epidermis, such as LCs, monocyte-derived LC-like cells, and inflammatory dendritic epidermal cells (IDECs). Of these, LC-like cells have been characterized in both human and mouse studies, while IDECs have only been described in human studies. This has shed a new light on the area of epidermal macrophages, suggesting that there might be a misidentification and misclassification of LCs. IDECs and LC-like cells have been shown to be present in both steady state and inflammatory state, but they are present in more significant amounts under inflammatory conditions such as atopic dermatitis, ultra violet injury, and psoriasis. In this review, we discuss what is already known and discuss the possible roles of LCs, LC-like cells, and IDECs during inflammation. Most intriguingly, we discuss the possibility of LCs having a dual identity as both a macrophage and a DC. This is shown as LCs are the only tissue-resident macrophage to have shown migratory property-like DCs.

Keywords: Langerhans cells, inflammatory dendritic epidermal cells, skin inflammation, resident macrophages, dendritic cells

\section{INTRODUCTION OF LANGERHANS CELLS (LCs)}

Langerhans cells are the only professional antigen-presenting cells that reside in the epidermis under steady-state conditions. They were first described by Paul Langerhans in 1868 as being part of the peripheral nervous system (1); however, recent studies have firmly placed LCs within the hematopoietic system (2-4). In the murine epidermal sheet, several cell populations are dendritic in shape, such as dendritic epidermal T cells (DETCs) and epidermal lymphoid cells (ELCs) (5). Although 
LCs have a similar shape, they are distinguished by the presence of birbeck granules in their cytoplasm (6). In recent years, the ontogeny of murine LCs has been studied and evidence has suggested that LCs are tissue-resident macrophages in the epidermal sheet. This is surprising as LCs have been shown to have dendritic cell (DC)-like properties such as migrating into the lymph node and the ability to prime T cells (7) leading to the assumption that LCs were part of the DC lineage. The migratory ability of LC is currently of interest and in debate as LCs are the only resident tissue-specific macrophages that have the ability to migrate into the lymph node. Thus, LCs are of special interest in the field of dermatology as their role in inflammation and infection of the skin is poorly understood.

\section{DEVELOPMENT OF LC}

During ontogenesis, primitive myeloid cells from the yolk sac (YS) seeds the skin and other tissues at around embryonic day (E) 7.5 by a process known as primitive hematopoiesis, through which the first wave of myeloid cells is defined (8). This first wave of cells is from the posterior plate mesoderm in the blood islands of extra-embryonic YS. At around E8.0, a second wave of hematopoietic progenitors called erytho-myeloid precursors (EMPs), which arise from the YS seed the skin. These EMPs are Myb transcription dependent, unlike the first wave, and this second wave of seeding is termed transient definitive hematopoiesis (9). From E8.5 onward, as the blood circulation is established, EMPs populate the fetal liver (FL) (10). During this time, FL-derived progenitors circulate into various tissues including the skin (11). LCs derived from primitive wave are diluted by FL progenitors, and FL derived LCs reside, expand, and self-maintain throughout adult life (12) (refer to Figure 1) $(13,14)$. LCs express definitive transcriptional factors Runx3 and $A h r(15,16)$ only at postnatal development (PND) day 2 (17). From PND day 2 onward, LCs go through a rapid expansion of about a 10 - to 20 -fold increase in population. They begin to express definitive cellular markers MHC class II and the C-type lectin receptor Langerin (CD207), and in 3 weeks, the adult LC network is established $(18,19)$. The differentiation of FL progenitors to LCs is highly dependent on the signaling pathway of cytokine transforming growth factor- $\beta$ (TGF- $\beta$ ), this has been shown in studies where ablation of LCs was observed in TGF- $\beta$ transcriptional factor Id 2 and Runx3deficient mice $(15,20)$. Cytokine interleukin-34 (IL-34) is recognized by colony-stimulating 1 factor receptor (M-CSFR), and M-CSFR is another important cytokine required for the full differentiation to LCs $(21,22)$. Keratinocytes on the epidermal layer have been shown to express both TGF- $\beta$ and IL-34, which support the differentiation into LCs, although LCs themselves have shown to have the ability to produce TGF- $\beta$. The TGF- $\beta$ derived from LCs acts directly on LCs through the autocrine/ paracrine signaling pathway and is required to facilitate their development and survival (23). Keratinocytes have been shown to play a pivotal role in controlling the position of LCs in different regions of the epidermis by the differential expression of $\alpha_{v} \beta_{6}$ and $\alpha_{v} \beta_{8}$ (24). Once the LC network is formed, LCs self-renew through life without the need of contribution from hematopoietic stem cell (HSC)-derived cell. Unlike most myeloid cells, LCs are radio-resistant and will not be ablated by irradiation (25).

At steady state, a small percentage of LCs have been shown to migrate into skin-draining lymph nodes (dLNs). Other than the role of maturation of LCs, TGF- $\beta$ has shown to inhibit LCs' migratory properties, and therefore, its availability determines LC homeostasis $(26,27)$. In order to maintain LC homeostasis, the conversion of LAP-TGF- $\beta$ into soluble TGF- $\beta$ by keratinocyte integrin $\alpha_{v} \beta_{6}$ and $\alpha_{v} \beta_{8}$ is required (24). To sustain its network, LCs replenish themselves through a constant, low-level of proliferation, which is similar to other types of tissue-resident macrophages $(19,28)$. However, unlike many other cell types, tissue-resident macrophages including LCs proliferate as a differentiated state, which is surprising given that the maintenance is controlled by the same self-renewal gene network (29). The key difference between stem cells and tissue-resident macrophages is that resident macrophages access its self-renewal gene network through macrophage-specific Maf transcriptional factors. Notably, stem cell progenitors are not required for LC network maintenance throughout life.

\section{LC DURING INFLAMMATION}

Many studies have been conducted to investigate the role of LCs during skin inflammation. The exposure to haptens and ultra violet (UV) light has long been the most popular way to study LC migration and activation. When LCs are activated, they have been shown to have a reduced expression of E-cadherin. E-cadherin is also expressed on keratinocytes and the downregulation of E-cadherin by LCs resembles the disengagement from keratinocytes for migration to the lymph node (30). The migration of LCs into the lymph node has shown to be an important mechanism for the induction of regulatory $\mathrm{T}$ cells (Treg). In this study, it has been demonstrated that UV exposure causes immunosuppression by the notable migration of LCs into the lymph node to induce antigen-specific Tregs following UV exposure (31). However, a contrasting study has shown that LCs were not required for UV-induced immunosuppression. Instead, dermal langerin ${ }^{+}$cells are responsible for the expansion of CD8 T cells, while the UV-induced migration of Treg into the lymph nodes was responsible for the inhibition of contact hypersensitivity (CHS) responses (32-34). The contrasting result is due to the difference in the methodology used. In the study conducted by Schwarz et al., they focused on the suppressive role of LCs during the sensitization phase, while the study by Wang et al. was referring to the suppression of the induction of CHS by UVR $(31,32)$.

To investigate the role of LCs during inflammation, researchers primarily used LC-deficient mouse models such as huLangerindiphtheria toxin A (DTA) (langerin-positive cells were knocked out by the expression of a DTA via a human promoter) and muLangerin-diphtheria toxin receptor (DTR) (langerin-positive cells express DTR and were depleted by injecting diphtheria toxin i.p.). These led to the conflicting results on the role of LCs during hapten-induced contact CHS. It was also shown that during the sensitization phase, LCs and langerin ${ }^{+}$dermal DCs play similar roles by presenting antigens to naive $\mathrm{T}$ cells to support their 

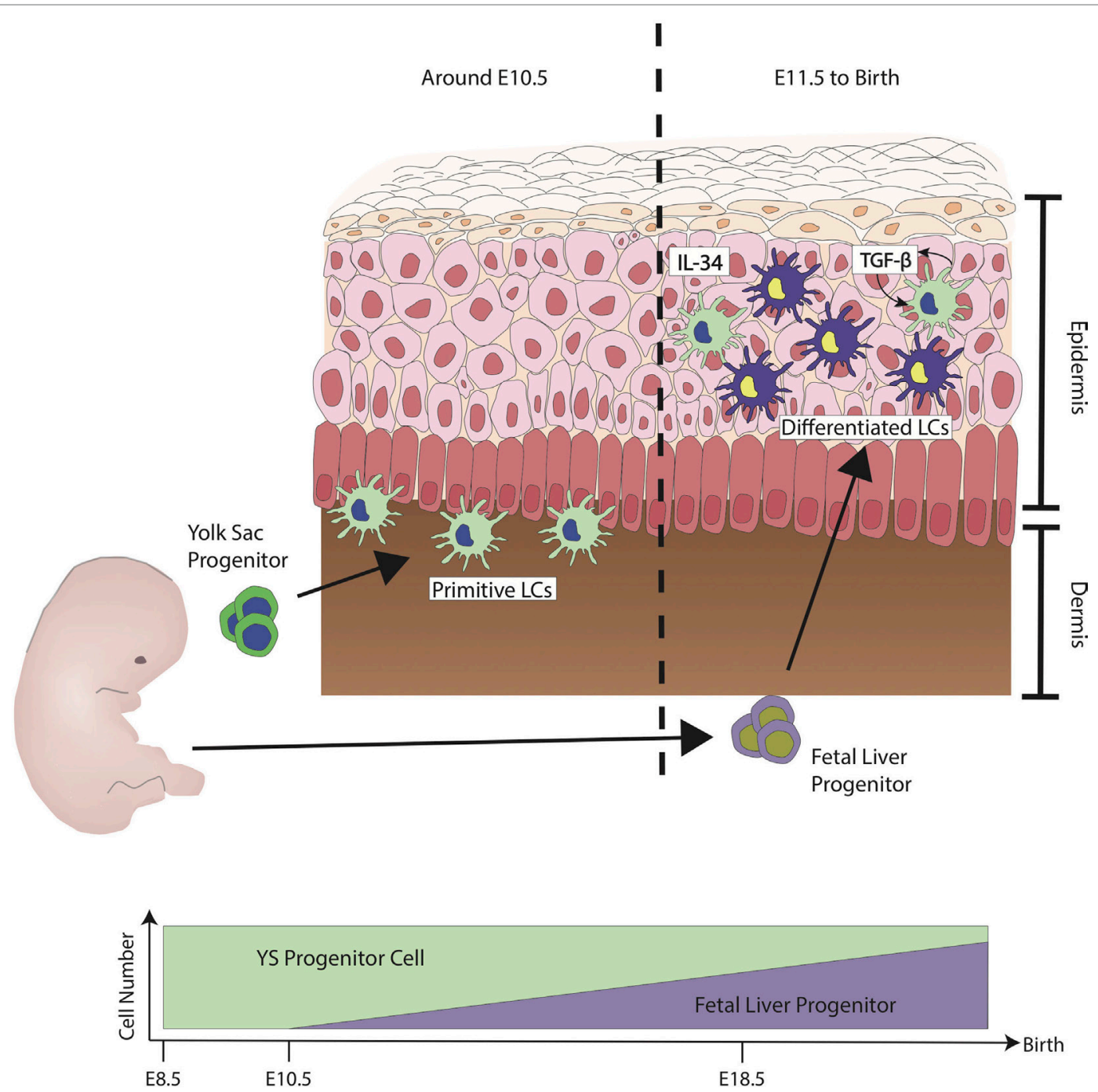

FIGURE 1 | Ontogeny of Langerhans cells (LCS) during steady state. The first wave of LCs that reside in the skin are from the yolk sac (YS) progenitors (green). They populate the skin but are unable to mature fully. At embryonic stage, LCs are immature due to the lack of signals from keratinocytes such as interleukin-34 (IL-34) and transforming growth factor- $\beta$ (TGF- $\beta$ ). LCs have shown to have the capability to produce TGF- $\beta$. TGF- $\beta$ derived from LCs acts directly on LCs through the autocrine/paracrine signaling pathway. At around E11.5, fetal liver progenitors (purple) start to populate the skin and, similar to the YS progenitors, they are still immature and sparsely distributed. Differentiation into LC has been observed from E18.5 onward, at the same time when keratinocytes start to fully differentiate. Upon birth, LCs have been observed to proliferate to form LC network. During steady state, LCs maintain their network by the low level of proliferation without much contribution from monocytes derived from the bone marrow. Figure adapted from Ginhoux et al. (13).

expansion and polarization $(35,36)$. This is further supported by Zahner et al. who demonstrated this by generating a Langerin-Cre TGF- $\beta$ R1 mouse model, which has a permanent LC deficiency, and showed a more tampered down CHS response as compared to WT. In Zahner et al.'s study, the regulatory role of LC was not demonstrated (37). When the role of LCs was investigated using the huLangerin-DTA/DTR ablation model, it was shown that LCs play an active role in suppressing immune responses. Conversely, in the muLangerin DTR model, not only did LCs not play a role in immunosuppression, they exacerbated the immune response to allergens $(38,39)$. In response to the conflicting results, human promoter-driven langerin-DTR mice (huLangerin-DTR) were created to investigate if the conflicting results were due to the method of ablation (inducible vs. constitutive ablation). By using
huLangerin-DTR mice, the author was able to ablate only LCs and not langerin-expressing dermal DCs, thereby demonstrating that LCs were indeed responsible for the suppression of immune reactions (40). These studies have shown that differing mouse models can lead to LCs taking on either inflammatory or anti-inflammatory roles. Further studies will be required to investigate the difference between the models and their impacts on LC function.

\section{CONTROVERSY WITH LC}

During skin inflammation, LCs are shown to be affected by having altered proliferation, maturation and migration rates. Migration during inflammation leads to a slight depletion of epidermal 
LCs, and this loss is compensated by the recruitment of bonemarrow-derived cells into the epidermis. Some monocytes have been shown to be capable of acquiring an LC-like phenotype $(41,42)$, and this has led to the hypothesis that during skin inflammation, LCs comprised cells with two distinct origins: resident LCs, which originate from the FL, and LC-like cells, which originate from the bone marrow and are only prominent in skin lesions. This has made elucidating the role of bona fide resident LCs very challenging.

In mice, the concept of two distinct populations of LCs has been shown by using an Id2-deficient mice. TGF- $\beta 1$ induces the expression of $I d 2$, which is essential for the development of LC network in the skin (20). Id2-deficient mice lack the LC network from birth, and reconstitution with wild-type mice bone marrow has shown that monocytes are able to differentiate into LC-like cells, supporting the presence of monocyte-derived LC-like cells (43). Skin inflammation causes GR-1 ${ }^{\text {high }}$ monocytes to be recruited into the skin and develop into LC-like cells (41). As described by Seré et al., recruited LC-like cells are termed as short-term LCs that are derived from Gr- $1^{\text {high }}$ monocytes in inflammatory conditions, LC-like cells do not require TGF- $\beta 1$ signaling, unlike bona fide resident LCs. These moLCs are deemed short term as they do not reside in the skin for a long time as compared to resident LCs. They are recruited into the epidermis to replenish the loss of resident LCs during inflammation and replaced by resident LCs once inflammation has stopped (43). In the same study, it was shown that there are two waves of LC recruitment during inflammation. The first wave, termed the inflammatory wave, consists of short-term LC, which are independent of $I d 2$, while the second wave, termed the steady-state wave, are long-term LCs, which are dependent on Id2. These highlight the existence of two types of LCs under inflammatory conditions. The differentiation of monocytes into LCs occurs 1 week after the induction of mild skin inflammation. GR-1 ${ }^{\text {hi }}$ monocyte develops into short-term LCs in an Id2independent manner. In contrast, long-term LCs are derived from LC precursors and require $I d 2$. These findings show the plasticity in the development of DC and reveal various ways in which LCs develop in steady-state as well as inflammatory conditions (43).

To add to the complexity of LCs, a human study conducted by Martínez-Cingolani et al. has shown that BDCA-1 ${ }^{+}$ peripheral blood monocytes of humans are the precursors to human LC-like cells. The differentiation of $\mathrm{BDCA}-1^{+} \mathrm{DCs}$ into human LC-like cells is driven by the expression of thymic stroma lymphopoietin (TSLP) and TGF- $\beta$, which are produced by keratinocytes in lesional skin of atopic dermatitis patients $(44,45)$. Interestingly, in her study, human LC-like cells have lower expressions of E-cadherin compared to resident bona fide LCs (44). This could suggest that these human LC-like cells readily migrate into the dLNs and have very little interaction with keratinocytes as compared to bona fide LCs (30). Since her study was conducted in an in vitro manner, she could only suggest that in an inflammatory state, BDCA-1+ blood DC are precursors to human LC-like cells. Further studies will be required to determine if these cells are similar to murine LC-like cells from Seré et al.'s study.
In the human study, the identification of another type of professional antigen-presenting cells has also been described; these recruited myeloid cells are termed inflammatory dendritic epidermal cells (IDECs) (46). The identification of IDECs was first described by Wollenberg et al. who observed that there were two distinct types of LCs in lesional skin of atopic eczema and other skin inflammatory diseases. He first identified the CD1a-positive population and then segregated the population by their FCeRI expression (47). The distribution of LC and IDECs in the skin is distinct, IDECs reside in the lower part of the epidermis, while bona fide resident LCs reside in the upper layer of the epidermis. The difference in location indicates a functional difference between IDECs and resident LCs. Due to the strategic location of LCs in the upper epidermal layer of the skin, they are able to capture antigens, which are located outside the tight junction (TJ) barrier by extending their dendrites through the TJ barrier (48). In contrast, IDECs residing in the lower layer of the epidermis are unable to capture antigens that are located on the surface of the skin because their dendrites extend horizontally (46).

Figure 2 illustrates the current hypothesis of the sequence of events, which occur when self-antigen/antigen initiates an immune response in a human model.

\section{THE DUAL IDENTITY OF LCs}

The dual identity of LCs as a macrophage and DC is a very intriguing phenomenon. The concept of macrophages being able to migrate into the lymph node has baffled immunologists and dermatologists alike for years. Recently, a study has been conducted by Wu et al., using Mafb-driven cre transgenic mice to identify whether DCs marked by the expression of Zbtb46-green fluorescent protein (GFP) express Mafb (49). Mafb is a transcriptional factor that is expressed specifically in the myeloid lineage of the hematopoietic system. Its upregulation is observed in differentiation from multipotent progenitors (MPP) to macrophages hence used to distinguish macrophages from other myeloid cells (50). In contrast, $Z b t b 46$ has been observed to be expressed in all classical DCs; therefore, $Z b t b 46$ has been used to distinguish classical DCs from all other types of immune cells $(51,52)$. However, $\mathrm{Wu}$ and his colleagues have found that only resident LCs from the epidermis express both Zbtb46 and Mafb simultaneously (49). This makes LCs a unique type of resident macrophage as it expresses both a DC and a macrophage-specific transcription factor. The mechanism of how LCs acquire DC transcriptional factor has yet to be fully understood and whether this population has a contamination with IDECs or LC-like cells has not yet been answered. The recent research conducted by Seré et al. and Martinez-Cingonali et al. hints that bona fide LC might have been mischaracterized during inflammation. Whether LCs indeed have a dual identity or have merely been mistakenly defined due to our limited knowledge of the plasticity of circulating monocytes into LC-like cells or IDECs have yet to be clarified.

\section{MIGRATORY CAPABILITY OF LC}

The migratory capability of LCs is tightly regulated by cytokines. IL-1 $\beta$, IL-18, and tumor necrosis factor $\alpha$ (TNF- $\alpha$ ) have been 


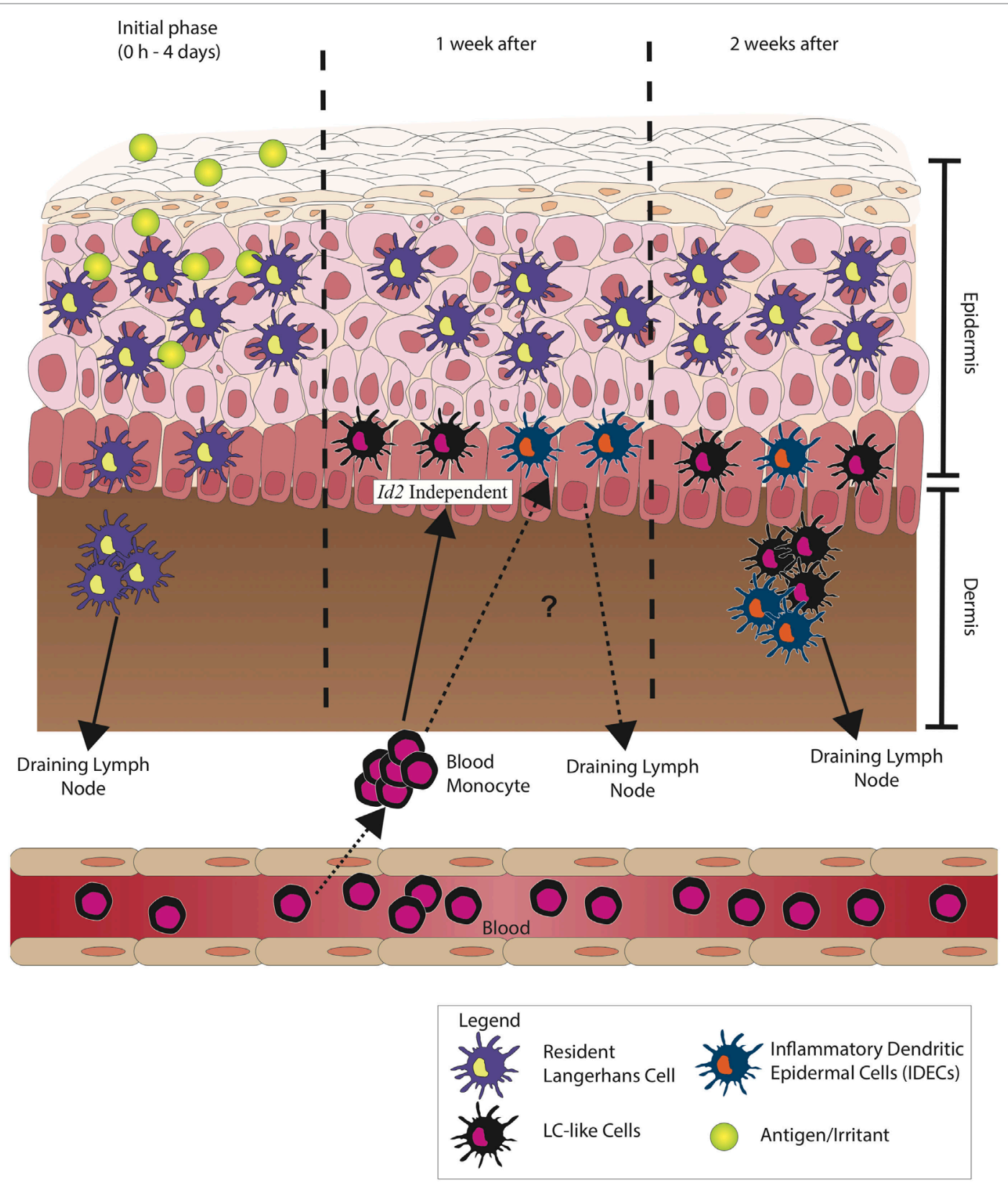

FIGURE 2 | Langerhans cells (LCs) during inflammation. During the initial phase of inflammation, LCs migrate to the draining lymph node, but unlike conventional/ classical dendritic cells (CDCs), LCs are observed to peak in number at day 4 after initial sensitization to antigen. The migration of LCs has been observed to be much slower. After 1 week, it is believed that inflammatory dendritic epidermal cells (IDECs) increase in number. These circulating blood monocytes from the bone marrow differentiate to LC-like cells and do not depend on transforming growth factor- $\beta$ (TGF- $\beta$ ) signaling pathway but are morphologically and phenotypically very similar to resident LCs. IDECs reside in the epidermal-dermal junction, and after 1 week of recruitment, they most likely migrate into the draining lymph node. These show the probable functional difference between LCs and IDECs as the kinetics of recruitment and migration between the two cells is different.

shown to control the migration of LCs out of the epidermis, and these cytokines are produced specifically by keratinocytes (53-55). It has also been shown that mice deficient in CCR7 have severe defects in LC migration to the skin-dLN, although this defect does not completely inhibit the migration of DC into lymph node (56-58). This suggests that there are CCR7-independent mechanisms, which allow the migration of DCs into lymph nodes.
Langerhans cell migration has been shown to be a two-step process, and the migration of LC into the dermis seems to be highly dependent on CXCR4-CXCL12 manner. CXCR4 has been shown to play a critical role in the maturation and migration of DCs into the lymph node (59). The blocking of CXCR4 has been shown to impair the immune response to antigen-specific CHS. This demonstrates the importance of chemokine CXCR4 in the 
role of effective cutaneous immune responses during CHS (59). During skin inflammation, the expression of TNF- $\alpha$ induces the expression of CXCL12 by dermal fibroblasts (60). This has been clearly demonstrated in the Ouwehand et al. study, where the migration of LC into the dermis was abrogated by CXCR4 and CXCL12 blocking antibodies (60). CCR7 did play a role in the migration of LCs from the epidermis to the dermal layer as the blocking of CCR7 ligands CCL19 and CCL21 did not affect the migration (60). To summarize, the migration of LCs into the lymph node has two phases, after the initial exposure to inflammatory stimuli such as hapten, LCs migrate into the dermis in a CXCR4-CXCL12-dependent manner but not reliant on CCR7. Once LCs have resided in the dermis, they upregulate their expression of CCR7, enter the lymphatic system, and migrate into the lymph node. These additional steps could be the reason for the delayed migration of LCs into the lymph node in comparison to dermal DCs. The CXCR4-CXCL12 axis governs LC migration to the $\mathrm{LN}$ in both mice and human, as shown in both studies $(59,60)$.

Although migration of dermal DCs and LCs has been well described by multiple studies, it has been challenging to accurately quantify the movement and lifespan of skin-derived DC subsets and LCs. The use of Kaede-transgenic mice has allowed researchers to investigate the exact kinetics of the migration of DCs and LCs into the dLNs. Kaede-transgenic mice express a green-to-red photoconvertible protein, Kaede (61). More recently, the use of KikGR mice has been used to track immune cell movement from the skin to the dLN after photoconversion. Similar to Kaede mice, KikGR fluorescence changes irreversibly from green to red upon exposure to violet light; as a result, KikGR mice have a greater photoconversion efficiency as compared to Kaede mice $(62,63)$. Tomura et al. were able to show the kinetics of LCs, CD103+ dermal DC, and CD103- into the dLN (64). After irritation, the number of LCs in dLN only peak from day 4 onward, as compared to $\mathrm{CD}_{103^{+}}$and $\mathrm{CD} 103^{-}$dermal DCs, which migrate to dLN almost immediately after irritation. Additionally, only photoconverted LCs migrated into the dLN, emphasizing the fact that LCs do not get replaced by blood-supplied precursors during steady state $(25,64)$.

Understanding the kinetics and mechanisms of LCs migration into the dLN is crucial as there is clear evidence suggesting that the skin is one of the main pathways that leads to developing systemic immunity by exogenous protein antigens (65). LCs have shown to have slower migration to the dLN as compared to the

\section{REFERENCES}

1. Langerhans P. Ueber die Nerven der menschlichen llaut. Arch Pathol Anat Physiol Klin Med (1868) 44:325-38. doi:10.1007/BF01959006

2. Rowden G, Lewis MG, Sullivan AK. Ia antigen expression on human epidermal Langerhans cells. Nature (1977) 268:192-3. doi:10.1038/268247a0

3. Klareskog L, Tjernlund U, Forsum U, Peterson PA. Epidermal Langerhans cells express Ia antigens. Nature (1977) 268:192-3.

4. Stingl G, Wolff-Schreiner E, Pichler WJ, Gschnait F, Knapp W. Epidermal Langerhans cell bear Fc and C3 receptors. Nature (1977) 267:192-3.

5. Almeida FF, Tenno M, Brzostek J, Li JL, Allies G, Hoeffel G, et al. Identification of a novel lymphoid population in the murine epidermis. Sci Rep (2015) 5:1-17. doi:10.1038/srep12554 dermal DCs, although the consequence of slower migration by antigen-presenting cells has yet to be evaluated. Additionally, in these kinetics studies, the possible role of IDEC and LC-like cells' migration into the dLN has yet to be discussed and studied. As we understand, IDECs and LC-like cells have very similar expression and phenotype as true resident LCs; therefore, it is difficult to evaluate if resident LC is solely responsible for antigen presentation in the dLN from the epidermis.

\section{CONCLUSION}

Langerhans cells are unique cells residing in the upper layer of the epidermis and are now regarded as part of the macrophage family due to its developmental pathway and ontogeny. LCs, as many other tissue-resident macrophages, arise from embryonic precursors and are maintained in the epidermis by low levels of proliferation and self-renewal in steady-state conditions. Unlike many other tissue-resident macrophages, LCs are the only macrophage that possess both DC and macrophage properties. They arise from embryonic precursors and survey antigens on the epidermal surface (properties, which are characteristic of macrophages); yet are able to migrate into the $\mathrm{dLN}$, which provides evidence that they share a functional blueprint with DCs. The dual identity of LCs substantiates the plasticity of LCs, although the molecular mechanisms and developmental pathways of a bona fide LC in the epidermis have yet to be clarified. LCs have also shown to have the capability to adapt to different immune stimuli in the skin, both in the areas of immunosuppression and in the pro-inflammatory responses. However, the presence of IDECs and LC-like cells coupled with the lack of identification and classification between these three cell types could have led to mischaracterization of the role of LCs during inflammation in past studies. Therefore, there is a need to explore the role of IDECs and LC-like cells in order to truly understand the role of LCs particularly during inflammation. This can lead to the discovery of novel immune modulators, which can be used for the treatment of inflammatory skin diseases.

\section{AUTHOR CONTRIBUTIONS}

MO wrote the mini review and contributed to the intellectual input and the structure of the review, GE and KK supervised the writing and the direction of the mini review, and GE and KK also contributed to the intellectual input and edited the mini review.

6. Valladeau J, Ravel O, Dezutter-Dambuyant C, Moore K, Kleijmeer M, Liu $\mathrm{Y}$, et al. Langerin, a novel C-type lectin specific to Langerhans cells, is an endocytic receptor that induces the formation of Birbeck granules. Immunity (2000) 12:71-81. doi:10.1016/S1074-7613(00)80160-0

7. Schuler G, Ralph MS. Murine epidermal Langerhans cells mature into potent immunostimulatory dendritic cells in vitro. J Exp Med (1985) 161:526-46. doi:10.1084/jem.161.3.526

8. Palis J, Robertson S, Kennedy M, Wall C, Keller G. Development of erythroid and myeloid progenitors in the yolk sac and embryo proper of the mouse. Development (1999) 126:5073-84.

9. Frame JM, McGrath KE, Palis J. Erythro-myeloid progenitors: "definitive" hematopoiesis in the conceptus prior to the emergence of hematopoietic stem cells. Blood Cells Mol Dis (2013) 51:220-5. doi:10.1016/j.bcmd.2013.09.006 
10. Palis J, Yoder MC. Yolk-sac hematopoiesis: the first blood cells of mouse and man. Exp Hematol (2001) 29:927-36. doi:10.1016/S0301-472X(01) 00669-5

11. Hoeffel G, Chen J, Lavin Y, Low D, Almeida FF, See P, et al. C-Myb erythromyeloid progenitor-derived fetal monocytes give rise to adult tissueresident macrophages. Immunity (2015) 42:665-78. doi:10.1016/j.immuni.2015. 03.011

12. Hoeffel G, Wang Y, Greter M, See P, Teo P, Malleret B, et al. Adult Langerhans cells derive predominantly from embryonic fetal liver monocytes with a minor contribution of yolk sac-derived macrophages. J Exp Med (2012) 209:1167-81. doi:10.1084/jem.20120340

13. Ginhoux F, Merad M. Ontogeny and homeostasis of Langerhans cells. Immunol Cell Biol (2010) 88:387-92. doi:10.1038/icb.2010.38

14. Ginhoux F, Guilliams M. Tissue-resident macrophage ontogeny and homeostasis. Immunity (2016) 44:439-49. doi:10.1016/j.immuni.2016.02.024

15. Fainaru O, Woolf E, Lotem J, Yarmus M, Brenner O, Goldenberg D, et al. Runx3 regulates mouse TGF- $\beta$-mediated dendritic cell function and its absence results in airway inflammation. EMBO J (2004) 23:969-79. doi:10.1038/sj. emboj.7600085

16. Jux B, Kadow S, Esser C. Langerhans cell maturation and contact hypersensitivity are impaired in aryl hydrocarbon receptor-null mice. J Immunol (2009) 182:6709-17. doi:10.4049/jimmunol.0713344

17. Mass E, Ballesteros I, Farlik M, Halbritter F, Günther P, Crozet L, et al. Specification of tissue-resident macrophages during organogenesis. Science (2016) 353:aaf4238. doi:10.1126/science.aaf4238

18. Tripp CH, Chang-Rodriguez S, Stoitzner P, Holzmann S, Stössel H, Douillard P, et al. Ontogeny of langerin/CD207 expression in the epidermis of mice. J Invest Dermatol (2004) 122:670-2. doi:10.1111/j.0022-202X.2004. 22337.x

19. Chorro L, Sarde A, Li M, Woollard KJ, Chambon P, Malissen B, et al. Langerhans cell (LC) proliferation mediates neonatal development, homeostasis, and inflammation-associated expansion of the epidermal LC network. J Exp Med (2009) 206:3089-100. doi:10.1084/jem.20091586

20. Hacker C, Kirsch RD, Ju X-S, Hieronymus T, Gust TC, Kuhl C, et al. Transcriptional profiling identifies Id 2 function in dendritic cell development. Nat Immunol (2003) 4:380-6. doi:10.1038/ni903

21. Wang Y, Szretter KJ, Vermi W, Gilfillan S, Rossini C, Cella M, et al. IL-34 is a tissue-restricted ligand of CSF1R required for the development of Langerhans cells and microglia. Nat Immunol (2012) 13:753-60. doi:10.1038/ ni. 2360

22. Greter M, Lelios I, Pelczar P, Hoeffel G, Price J, Leboeuf M, et al. Stroma-derived interleukin-34 controls the development and maintenance of Langerhans cells and the maintenance of microglia. Immunity (2012) 37:1050-60. doi:10.1016/j. immuni.2012.11.001

23. Kaplan DH, Li MO, Jenison MC, Shlomchik WD, Flavell RA, Shlomchik MJ. Autocrine/paracrine TGF $\beta 1$ is required for the development of epidermal Langerhans cells. J Exp Med (2007) 204:2545-52. doi:10.1084/jem.20071401

24. Mohammed J, Beura LK, Bobr A, Astry B, Chicoine B, Kashem SW, et al. Stromal cells control the epithelial residence of DCs and memory T cells by regulated activation of TGF- $\beta$. Nat Immunol (2016) 17:414-21. doi:10.1038/ ni.3396

25. Merad M, Manz MG, Karsunky H, Wagers A, Peters W, Charo I, et al. Langerhans cells renew in the skin throughout life under steady-state conditions. Nat Immunol (2002) 3:1135-41. doi:10.1038/ni852

26. Bobr A, Igyarto BZ, Haley KM, Li MO, Flavell RA, Kaplan DH. Autocrine/ paracrine TGF- $\beta 1$ inhibits Langerhans cell migration. Proc Natl Acad Sci U S A (2012) 109:10492-7. doi:10.1073/pnas.1119178109

27. Kel JM, Girard-Madoux MJH, Reizis B, Clausen BE. TGF- $\beta$ is required to maintain the pool of immature Langerhans cells in the epidermis. J Immunol (2010) 185:3248-55. doi:10.4049/jimmunol.1000981

28. Ghigo C, Mondor I, Jorquera A, Nowak J, Wienert S, Zahner SP, et al. Multicolor fate mapping of Langerhans cell homeostasis. J Exp Med (2013) 210:1657-64. doi:10.1084/jem.20130403

29. Soucie EL, Weng Z, Geirsdóttir L, Molawi K, Maurizio J, Fenouil R, et al. Lineage-specific enhancers activate self-renewal genes in macrophages and embryonic stem cells. Science (2016) 351:aad5510. doi:10.1126/science.aad5510

30. Tang A, Amagai M, Granger LG, Stanley JR, Udey MC. Adhesion of epidermal Langerhans cells to keratinocytes mediated by E-cadherin. Nature (1993) 361:82-5. doi:10.1038/361082a0
31. Schwarz A, Noordegraaf M, Maeda A, Torii K, Clausen BE, Schwarz T. Langerhans cells are required for UVR-induced immunosuppression. J Invest Dermatol (2010) 130:1419-27. doi:10.1038/jid.2009.429

32. Wang L, Jameson SC, Hogquist KA. Epidermal Langerhans cells are not required for UV-induced immunosuppression. J Immunol (2009) 183:5548-53. doi:10.4049/jimmunol.0900235

33. Schwarz A, Navid F, Sparwasser T, Clausen BE, Schwarz T. In vivo reprogramming of UV radiation-induced regulatory T-cell migration to inhibit the elicitation of contact hypersensitivity. J Allergy Clin Immunol (2011) 128:826-33. doi:10.1016/j.jaci.2011.06.005

34. Schwarz T. The dark and the sunny sides of UVR-induced immunosuppression: photoimmunology revisited. J Invest Dermatol (2009) 130:49-54. doi:10.1038/jid.2009.217

35. Honda T, Nakajima S, Egawa G, Ogasawara K, Malissen B, Miyachi Y, et al. Compensatory role of Langerhans cells and langerin-positive dermal dendritic cells in the sensitization phase of murine contact hypersensitivity. J Allergy Clin Immunol (2010) 125:1154-6. doi:10.1016/j.jaci.2009.12.005

36. Noordegraaf M, Flacher V, Stoitzner P, Clausen BE. Functional redundancy of langerhans cells and langerin + dermal dendritic cells in contact hypersensitivity. J Invest Dermatol (2010) 130:2752-9. doi:10.1038/jid.2010.223

37. Zahner SP, Kel JM, Martina CAE, Brouwers-Haspels I, van Roon MA, Clausen BE. Conditional deletion of TGF- $\beta$ R1 using Langerin-cre mice results in Langerhans cell deficiency and reduced contact hypersensitivity. J Immunol (2011) 187:5069-76. doi:10.4049/jimmunol.1101880

38. Kissenpfennig A, Henri S, Dubois B, Laplace-Builhé C, Perrin P, Romani N, et al. Dynamics and function of langerhans cells in vivo: dermal dendritic cells colonize lymph node areasdistinct from slower migrating langerhans cells. Immunity (2005) 22:643-54. doi:10.1016/j.immuni.2005.04.004

39. Bennett CL, Van Rijn E, Jung S, Inaba K, Steinman RM, Kapsenberg ML, et al. Inducible ablation of mouse Langerhans cells diminishes but fails to abrogate contact hypersensitivity. J Cell Biol (2005) 169:569-76. doi:10.1083/ jcb.200501071

40. Bobr A, Olvera-Gomez I, Igyarto BZ, Haley KM, Hogquist KA, Kaplan DH. Acute ablation of Langerhans cells enhances skin immune responses. J Immunol (2010) 185:4724-8. doi:10.4049/jimmunol.1001802

41. Ginhoux F, Tacke F, Angeli V, Bogunovic M, Loubeau M, Dai XM, et al. Langerhans cells arise from monocytes in vivo. Nat Immunol (2006) 7:265-73. doi:10.1038/ni1307

42. Nagao K, Kobayashi T, Moro K, Ohyama M, Adachi T, Kitashima DY, et al. Stress-induced production of chemokines by hair follicles regulates the trafficking of dendritic cells in skin. Nat Immunol (2012) 13:744-52. doi:10.1038/ ni. 2353

43. Seré K, Baek JH, Ober-Blöbaum J, Müller-Newen G, Tacke F, Yokota Y, et al. Two distinct types of Langerhans cells populate the skin during steady state and inflammation. Immunity (2012) 37:905-16. doi:10.1016/j. immuni.2012.07.019

44. Martinez-Cingolani C, Grandclaudon M, Jeanmougin M, Jouve M, Zollinger R, Soumelis V. Human blood BDCA-1 dendritic cells differentiate into Langerhanslike cells with thymic stromal lymphopoietin and TGF-beta. Blood (2014) 124:2411-20. doi:10.1182/blood-2014-04-568311

45. Soumelis V, Reche PA, Kanzler H, Yuan W, Edward G, Homey B, et al. Human epithelial cells trigger dendritic cell-mediated allergic inflammation by producing TSLP. Nat Immunol (2002) 3:673-80. doi:10.1038/ni805

46. Yoshida K, Kubo A, Fujita H, Yokouchi M, Ishii K, Kawasaki H, et al. Distinct behavior of human Langerhans cells and inflammatory dendritic epidermal cells at tight junctions in patients with atopic dermatitis. JAllergy Clin Immunol (2014) 134:856-64. doi:10.1016/j.jaci.2014.08.001

47. Wollenberg A, Kraft S, Hanau D, Bieber T. Immunomorphological and ultrastructural characterization of Langerhans cells and a novel, inflammatory dendritic epidermal cell (IDEC) population in lesional skin of atopic eczema. J Invest Dermatol (1996) 106:446-53. doi:10.1111/1523-1747.ep12343596

48. Ouchi T, Kubo A, Yokouchi M, Adachi T, Kobayashi T, Kitashima DY, et al. Langerhans cell antigen capture through tight junctions confers preemptive immunity in experimental staphylococcal scalded skin syndrome. J Exp Med (2011) 208:2607-13. doi:10.1084/jem.20111718

49. Wu X, Briseño CG, Durai V, Albring JC, Haldar M, Bagadia P, et al. Mafb lineage tracing to distinguish macrophages from other immune lineages reveals dual identity of Langerhans cells. J Exp Med (2016) 213(12):2553-65. doi:10.1084/jem.20160600 
50. Kelly LM. MafB is an inducer of monocytic differentiation. EMBO J (2000) 19:1987-97. doi:10.1093/emboj/19.9.1987

51. Meredith MM, Liu K, Darrasse-Jeze G, Kamphorst AO, Schreiber HA, Guermonprez P, et al. Expression of the zinc finger transcription factor zDC (Zbtb46, Btbd4) defines the classical dendritic cell lineage. J Exp Med (2012) 209:1153-65. doi:10.1084/jem.20112675

52. Satpathy AT, KC W, Albring JC, Edelson BT, Kretzer NM, Bhattacharya D, et al. Zbtb46 expression distinguishes classical dendritic cells and their committed progenitors from other immune lineages. JExp Med (2012) 209:1135-52. doi:10.1084/jem.20120030

53. Cumberbatch M, Dearman RJ, Kimber I. Langerhans cell migration in mice requires intact type I interleukin 1 receptor (IL-1RI) function. Arch Dermatol Res (1999) 291:357-61. doi:10.1007/s004030050422

54. Cumberbatch M, Kimber I. Tumour necrosis factor-alpha is required for accumulation of dendritic cells in draining lymph nodes and for optimal contact sensitization. Immunology (1995) 84:31-5.

55. Cumberbatch M, Dearman RJ, Kimber I. Langerhans cells require signals from both tumour necrosis factor-alpha and interleukin-1 beta for migration. Immunology (1997) 92:388-95. doi:10.1046/j.1365-2567.1997.00360.x

56. Förster R, Schubel A, Breitfeld D, Kremmer E, Renner-Müller I, Wolf E, et al. CCR7 coordinates the primary immune response by establishing functional microenvironments in secondary lymphoid organs. Cell (1999) 99:23-33. doi:10.1016/S0092-8674(00)80059-8

57. Ohl L, Mohaupt M, Czeloth N, Hintzen G, Kiafard Z, Zwirner J, et al. CCR7 governs skin dendritic cell migration under inflammatory and steady-state conditions. Immunity (2004) 21:279-88. doi:10.1016/j.immuni.2004.06.014

58. Gunn MD, Kyuwa S, Tam C, Kakiuchi T, Matsuzawa A, Williams LT, et al. Mice lacking expression of secondary lymphoid organ chemokine have defects in lymphocyte homing and dendritic cell localization. J Exp Med (1999) 189:451-60. doi:10.1084/jem.189.3.451

59. Kabashima K, Shiraishi N, Sugita K, Mori T, Onoue A, Kobayashi M, et al. CXCL12-CXCR4 engagement is required for migration of cutaneous dendritic cells. Am J Pathol (2007) 171:1249-57. doi:10.2353/ajpath.2007.070225
60. Ouwehand K, Santegoets SJAM, Bruynzeel DP, Scheper RJ, de Gruijl TD, Gibbs S. CXCL12 is essential for migration of activated Langerhans cells from epidermis to dermis. Eur J Immunol (2008) 38:3050-9. doi:10.1002/ eji.200838384

61. Tomura M, Yoshida N, Tanaka J, Karasawa S, Miwa Y, Miyawaki A, et al. Monitoring cellular movement in vivo with photoconvertible fluorescence protein "Kaede" transgenic mice. Proc Natl Acad Sci U S A (2008) 105:10871-6. doi:10.1073/pnas.0802278105

62. Tsutsui H, Karasawa S, Shimizu H, Nukina N, Miyawaki A. Semi-rational engineering of a coral fluorescent protein into an efficient highlighter. $E M B O$ Rep (2005) 6:233-8. doi:10.1038/sj.embor.7400361

63. Nowotschin S, Hadjantonakis AK. Use of KikGR a photoconvertible greento-red fluorescent protein for cell labeling and lineage analysis in ES cells and mouse embryos. BMC Dev Biol (2009) 9:49. doi:10.1186/1471-213X-9-49

64. Tomura M, Hata A, Matsuoka S, Shand FHW, Nakanishi Y, Ikebuchi R, et al. Tracking and quantification of dendritic cell migration and antigen trafficking between the skin and lymph nodes. Sci Rep (2014) 4:1-11. doi:10.1038/ srep06030

65. Hsieh KY, Tsai CC, Herbert Wu CH, Lin RH. Epicutaneous exposure to protein antigen and food allergy. Clin Exp Allergy (2003) 33:1067-75. doi:10.1046/ j.1365-2222.2003.01724.x

Conflict of Interest Statement: The authors declare that the research was conducted in the absence of any commercial or financial relationships that could be construed as a potential conflict of interest.

Copyright $(2018$ Otsuka, Egawa and Kabashima. This is an open-access article distributed under the terms of the Creative Commons Attribution License (CC BY). The use, distribution or reproduction in other forums is permitted, provided the original author(s) and the copyright owner(s) are credited and that the original publication in this journal is cited, in accordance with accepted academic practice. No use, distribution or reproduction is permitted which does not comply with these terms. 